\title{
A Ciência da Informação e a sociedade brasileira: algumas representações de pesquisadores da área'
}

\author{
The Information Science and the Brazilian society: \\ Some representations of the area researchers
}

Carlos Cândido de ALMEIDA²

RESUMO

São relatados neste artigo, os resultados de pesquisas com foco nas representações do campo da Ciência da Informação, produzidas pelos pesquisadores classificados como pertencentes a essa área de conhecimento. O objetivo central do estudo foi conhecer as representações - conhecimentos construídos socialmente por uma comunidade ou grupo de sujeitos - do campo da Ciência da Informação, expressas por seus pesquisadores no Brasil. Esta pesquisa enquadra-se no tipo qualitativo e o método utilizado constou da coleta, análise e interpretação dos discursos do grupo de pesquisadores selecionados. Após a análise dos discursos, chegou-se, entre outros resultados, às representações referentes à relação do campo da Ciência da Informação com a sociedade brasileira. Conclui-se, a partir do discurso dos pesquisadores, que o campo da Ciência da Informação esteve, desde sua origem, distante da realidade nacional.

Palavras-chave: representações sociais; campo científico; pesquisadores - Ciência da Informação; sociedade brasileira.

\begin{abstract}
A B STRACT
This article reports the results of researches on the representations of the Information Science field, produced by researchers belonging to this area of knowledge. The representations are socially constructed knowledge, created by a community or group of subjects. The aim of this study was to get accquainted with the representations in the field of Information Science expressed by the researchers of the area in Brazil. This research fits into the qualitative type, and the research method consisted of assessing, analyzing, and interpreting the discourses originated by the group of selected researchers. After the discourse analysis, this study came to some results, central to which were the representations of the relationship between the field of Information Science and the Brazilian society. From such researchers'discourse, the article concludes, that the field of Information Science has been, since its origin, quite distant from Brazilian society reality.
\end{abstract}

Key words: social representations; scientific field; researchers - Information Science; Brazilian society.

\footnotetext{
1 Este artigo resume alguns resultados da pesquisa intitulada "O campo da ciência da informação: suas representações no discurso coletivo dos pesquisadores do campo no Brasil", desenvolvida sob a orientação do professor Dr. Francisco das Chagas de Souza no Programa de Pós-Graduação em Ciência da Informação (PGCIN) da Universidade Federal de Santa Catarina (UFSC). Contou com o apoio da Coordenação de Aperfeiçoamento de Pessoal de Nível Superior (CAPES).

2 Mestre em Ciência da Informação, Professor, Departamento de Biblioteconomia e História, Universidade Federal do Rio Grande. Rua Engenheiro Alfredo Huch, 475, Centro, 96201-900, Rio Grande, RS, Brasil. E-mail: <karl_almeida@yahoo.com.br>.

Recebido em 20/3/2006 e aceito para publicação em 9/8/2006.
}

TransInformação, Campinas, 18(3):169-180, set./dez., 2006 


\section{N T R O D U Ç Ã O}

A Ciência da Informação é um produto da atividade humana que está sendo construído pelos agentes sociais (pesquisadores, profissionais, instituições de ensino e fomento, associações profissionais e científicas, estados e instituições multilaterais) envolvidos com o ensino, a pesquisa e as práticas de organização e recuperação da informação. A existência e o desenvolvimento desses grupos de agentes são regulados socialmente. Essa ciência se dedica ao estudo da informação e às relações sociais envolvidas com os processos de tratamento e acesso.

A estruturação da Ciência da Informação pressupõe, além dos agentes sociais, a divulgação de seu papel junto à sociedade e a propagação das concepções manifestas em sua comunidade entre os próprios pares do campo científico. Segundo Bourdieu (1983, 2004), campo científico, do qual participam agentes sociais, é um espaço social de lutas entre os cientistas ou pesquisadores, cada um em busca da manutenção ou reestruturação das relações de poder dentro dos limites desse espaço. Nessa lógica, os cientistas mantêm relações antagônicas, de parceria e de competitividade; os cientistas estabelecidos em posições confortáveis no campo são os competidores com mais vantagens em relação aos seus pares situados em condição inferior. Os bem colocados no campo buscam garantir o poder de ordenar as normas, os critérios de cientificidade e os requisitos para o acesso dos novatos a esses recintos. Os novatos ou iniciantes no jogo de competição buscam quebrar a relação de poder preestabelecida e impor sua visão de mundo, o que lhes possibilitará alcançar prestígio e obter a faculdade de reordenar novamente o campo e, assim, ditar o que deve ser considerado como realmente científico para os demais membros da comunidade.

Entende-se que a Ciência da Informação é um espaço social de produção de conhecimento, e o conceito de campo é empregado para designar as particularidades das relações subjacentes entre os participantes nas possíveis lutas. O campo científico representa um espaço de confrontos entre pesquisadores. É pensado, na perspectiva de Bourdieu (1983, 2004), como uma arena de lutas em busca ou em defesa do monopólio da produção científica. Esse espaço social é também regido pela soma das forças e ações das instituições produtoras de conhecimentos, dos seus mecanismos e critérios de validação de cursos, promoção de pesquisadores, de financiamento a pesquisas e de seleção de aspirantes a investigadores. Sendo uma construção social, presume-se que exista a comunicação entre os pares para estabelecer efetivamente as finalidades e o alcance da Ciência da Informação na sociedade.

As interações sociais contribuem para efetivar a construção dessa realidade, possibilitando trocar elementos comuns entre os interagentes. Segundo Berger e Luckmann (2002), para a construção social da realidade é indispensável a interação social como meio de divulgar os conhecimentos que conferem a noção de realidade aos grupos humanos. Dessa forma, membros de um grupo (como a comunidade científica) interagem com o intuito de projetar seu arquétipo de realidade tal como é experienciado pelo conjunto de integrantes dessa comunidade.

Considera-se que os cientistas são os sujeitos que, em uma ciência, constroem os critérios de cientificidade e os divulgam por meio de artigos científicos, livros, palestras, comunicação informal e outras formas de veicular suas pesquisas e impressões do que acreditam ser o conhecimento científico. No caso da Ciência da Informação não seria diferente. Pesquisadores e instituições sociais (associações, agências de fomento, etc.) contribuem para a concepção que seus pares têm dessa ciência e oferecem subsídios para o entendimento que os profissionais ligados à área terão desse campo.

A posição ocupada pelos pesquisadores e pelas instituições sociais de fomento à pesquisa é estratégica para a formulação de discursos que representam a realidade social da Ciência da Informação. Nesse sentido, investigar o que e como pensam os sujeitos ligados às instituições mais representativas no que diz respeito ao fomento à pesquisa pode, em certa medida, resgatar alguns aspectos da dinâmica dos pensamentos enraizados nesse campo.

Buscando ampliar um pouco essa discussão, foi realizada uma pesquisa que teve como objetivo principal conhecer as representações da Ciência da Informação produzidas e expressas por seus pesquisadores no país.

Este artigo limita-se a apresentar a análise das ancoragens do discurso do coletivo de sujeitos consultados, pertinentes às relações da Ciência da 
Informação com a sociedade brasileira, bem como a fala do grupo sobre a história desse campo no país. Antes, porém, será necessário pontuar alguns elementos básicos da história dessa ciência e detalhar os procedimentos metodológicos utilizados na realização do estudo.

\section{A C I Ê N I A D A I NF O R M A Ç Ã O NOB RASIL}

No Brasil, a Documentação precedeu a Ciência da Informação, assim como ocorreu nos Estados Unidos e em países da Europa. A Documentação, de base européia, teve suas idéias difundidas no país, passando a compor nomes de centros de documentação e de escolas profissionais de Biblioteconomia.

A presença da Documentação data das primeiras políticas de informação brasileiras e, segundo resgata Castro (2000, p.243), "a preocupação de estabelecer políticas de informação no país tem sua gênese em Peregrino da Silva, diretor da Biblioteca Nacional de 1900 a 1921 [...]". Posteriormente, as ações subscritas à Documentação foram desempenhadas pela Fundação Getúlio Vargas (FGV) e pelo Departamento Administrativo do Serviço Público (DASP) (CASTRO, 2000, p.242).

O relacionamento do governo brasileiro com a Organização das Nações Unidas para Educação, Ciência e Cultura (Unesco) significou, por outro lado, a ampliação das discussões da educação em Ciência da Informação no país. Muitas das concepções de políticas de informação da Unesco foram acolhidas e influenciaram os debates empreendidos pelos profissionais brasileiros.

O Instituto Brasileiro de Bibliografia e Documentação (IBBD), desde sua fundação, em 1954, reconheceu a necessidade de capacitar pessoal para lidar com a documentação científica especificamente na elaboração de bibliografias nacionais da produção bibliográfica das várias ciências. Com esse intuito, desde 1956 oferece o Curso de Documentação Científica. Outro condicionante do desenvolvimento da Documentação e da Ciência da Informação no Brasil foi o ambiente político da instituição do Curso de Mestrado em Ciência da Informação do IBBD, que incentivou a criação de sistemas e redes de informação científica entre os institutos de pesquisa nacionais. Tratando de reconstituir essa época, Vieira (1995, on-line) comenta: "se de um lado a política brasileira, nos anos 70, era restritiva em função da ditadura militar, de modo contraditório gerou o desenvolvimento dos sistemas de informação científica e tecnológica e a criação de novos cursos de pós-graduação em Biblioteconomia [...]".

Além disso, deve-se salientar a influência da literatura inglesa na Ciência da Informação brasileira, decorrente sobremaneira da fundação do Curso de Mestrado do IBBD com professores, em sua maioria, dos Estados Unidos e da Inglaterra.

É importante salientar que a Ciência da Informação despertou o interesse da categoria bibliotecária devido aos conhecimentos gerados nesse campo e por todo o status que um dia chegaria à categoria assim que se adotassem procedimentos reconhecidos e imprescindíveis para a administração da informação nos espaços estratégicos da sociedade, isto é, tecnologias de recuperação da informação e novos métodos de tratamento da informação em unidades de informação especializada. Com ambiente favorável para aceitação de conhecimentos e das técnicas da Ciência da Informação, tornou-se fácil a incursão dessa ciência no interior de outras áreas estabelecidas, como, por exemplo, da Biblioteconomia, que amparou mais rapidamente as recentes idéias do novo campo. Aos poucos, a Biblioteconomia abrigou conteúdos da Ciência da Informação, como também o fez com a Documentação (LEMOS, 1972; CASTRO, 2000).

No final da década de 1970, uma concepção oficial de Ciência da Informação é divulgada no documento Avaliação e Perspectiva do Conselho Nacional de Desenvolvimento Científico e Tecnológico (CNPq) (OLIVEIRA, 2001, p.143). Essa concepção de Ciência da Informação teve grande impacto sobre a comunidade científica da Ciência da Informação no país, principalmente para as áreas incluídas como subdisciplinas dessa ciência. Nesse sentido, "Ciência da informação designa um campo mais amplo, de propósitos investigativos e analíticos, interdisciplinar por natureza, que tem por objetivo o estudo dos fenômenos ligados à produção, organização, difusão e utilização da informação em todos os campos do saber." (OLIVEIRA, 2001, p.143).

Além desse amplo escopo, é estabelecida uma relação hierárquica com outras áreas. A Ciência da 
Informação abriga a Biblioteconomia e a Arquivologia como disciplinas que têm em comum a recuperação da informação (OLIVEIRA, 2001, p.144). É com essa definição que a agência compreende a Ciência da Informação, entretanto a concepção não reflete as referidas áreas, nem mesmo se identifica com elas. Alguns artigos publicados em periódicos da área manifestaram a recusa em adotar esse entendimento de Ciência da Informação. Para Dias (2000, 2002), a idéia não representa o ideal da Biblioteconomia nem mesmo compreenderia uma área tão vasta dos estudos da informação, por isso prefere a expressão "Biblioteconomia e Ciência da Informação". Fonseca (2002) ressalta sua preocupação com a posição aglutinadora das agências de fomento nacionais, além de demonstrar que a Arquivologia não adotou, por completo, a informação como objeto e que os teóricos da Ciência da Informação desconsideram as relações com a Arquivologia.

Em 1989, funda-se a Associação Nacional de Pesquisa e Pós-Graduação em Ciência da Informação e Biblioteconomia (ANCIB), decorrente do esforço conjunto de alguns cursos e programas de pós-graduação do campo. A ANCIB tem por finalidade incentivar as atividades de ensino de pós-graduação e de pesquisa em Ciência da Informação (ASSOCIAÇÃO..., 2004). É de responsabilidade da associação a organização do Encontro Nacional de Pesquisa da ANCIB, que reúne pesquisadores para debates e reflexões a respeito de temas especializados em Ciência da Informação.

Na década de 1990, com a abertura de programas de doutoramento em Ciência da Informação, formaram-se os primeiros doutores-pesquisadores em Ciência da Informação em programas brasileiros. Subentende-se que isso deveria refletir um amadurecimento nas pesquisas e na produção científica em geral. Esses pesquisadores em Ciência da Informação ainda são em número reduzido, tendo em vista que os programas de pós-graduação foram, em sua maioria, iniciados na segunda metade da década de 1990.

Uma fonte interessante para referir-se à definitiva inserção da Ciência da Informação no Brasil foi a remodelação de cursos de mestrado e doutorado em Biblioteconomia. Esses cursos de pós-graduação, a partir dos anos de 1990, passaram a ser designados como programas de pós-graduação em Ciência da Informação.
A segunda metade da década de 1990 sinalizou para a consolidação definitiva das expressões "ciência da informação" e "informação" junto ao ensino de graduação em Biblioteconomia no país. Isso se deveu à mudança dos nomes dos departamentos, à criação de ênfases e/ou habilitações nos tradicionais cursos de Biblioteconomia e à abertura de cursos de graduação específicos em Ciência e Gestão da Informação. No entanto, muitas escolas e departamentos de Biblioteconomia já possuíam disciplinas específicas em Documentação e Ciência da Informação.

Em estudo apresentado em 2003, as pesquisadoras Población e Noronha (2003) computaram 1176 (1081 mestres e 95 doutores) pesquisadores formados em programas nacionais de pós-graduação em Ciência da Informação, até dezembro de 2002. Entretanto, segundo as autoras, a quantidade de pesquisadores está aumentando a cada ano devido à abertura de novos programas de pós-graduação. Além disso, é relevante notar que o grupo de pesquisadores em Ciência da Informação no Brasil também é composto por doutores e mestres formados em programas de pós-graduação em Ciência da Informação de outros países e em programas de pós-graduação de outras áreas, no país e no exterior. Em virtude disso, acredita-se que o número supere os 1176 pesquisadores contados no estudo de Población e Noronha (2003). Assim, entende-se que tais aspectos foram determinantes na institucionalização do campo dessa ciência no país.

\section{MÉTODOS}

Tendo em vista resgatar as representações elaboradas coletivamente pelos pesquisadores em Ciência da Informação no Brasil, valeu-se de procedimentos e estratégias metodológicas que evidenciam as representações do grupo, bem como da fundamentação teórica dos estudos das representações sociais de Moscovici (2003), que, de modo geral, busca explicar como as representações presentes em uma coletividade correspondem aos pensamentos que orientam as ações dos indivíduos.

$\mathrm{Na}$ teoria das representações sociais de Moscovici, o objetivo das representações é transformar o não familiar em familiar, reconhecer objetos que não se comportam como as formas ideais ou já 
conhecidas pelo indivíduo (MOSCOVICI, 2003, p.54). Para que o conhecimento de algo seja iniciado, é necessário utilizar esse processo de familiarização, isto é, relacionar o considerado estranho a uma categoria preestabelecida. Os processos fundamentais na geração das representações sociais são: ancoragem e objetivação.

Por ancoragem Moscovici (2003, p.61) entende "[...] um processo que transforma algo estranho e perturbador, que nos instiga, em nosso sistema particular de categorias e o compara com um paradigma de uma categoria que nós pensamos ser apropriada." O processo de ancoragem é composto por outros dois processos: a classificação e a nomeação, que visam ao reconhecimento do desconhecido. Classificar é incluir numa categoria familiar um objeto estranho, dando-lhe oportunidade de se relacionar a outros objetos do mesmo gênero ou de gêneros semelhantes. A nomeação difere da classificação, mas é imprescindível para se classificar. "Ao nomear algo, nós o libertamos de um anonimato perturbador, para dotá-lo de uma genealogia e para incluí-lo em um complexo de palavras específicas, para localizá-lo, de fato, na matriz de identidade de nossa cultura." (MOSCOVICI, 2003, p.66).

A objetivação é o processo pelo qual a realidade anteriormente estranha torna-se, além de conhecida, verificável a ponto de ser incontestável. Assim, "[...] o que é incomum e imperceptível para uma geração, torna-se familiar e óbvio para a seguinte [...]. Objetivação une a idéia de não-familiaridade com a realidade, torna-se a verdadeira essência da realidade" (MOSCOVICI, 2003, p.71). A objetivação transforma a representação familiarizada recentemente em representação da realidade após certo tempo. Por exemplo, Moscovici (2003, p.72) demonstra, referindo-se ao seu estudo clássico relativo às representações da psicanálise, como terminologias aplicáveis nas teorias psicanalíticas, especificamente o termo "complexidade", foram transformadas pelo senso comum de modo a expressar no interior de cada grupo analisado uma realidade incontestável e verificável. Nesse sentido, a "[...] imagem do conceito deixa de ser signo e torna-se a réplica da realidade, um simulacro, no verdadeiro sentido da palavra. A noção, pois, ou a entidade da qual ela proveio, perde seu caráter abstrato, arbitrário e adquire uma existência quase física, independente."
(MOSCOVICI, 2003, p.74). A objetivação, nas palavras de Oliveira e Werba (2002, p.109), "[...] é o processo pelo qual procuramos tornar concreto, visível, uma realidade. Procuramos aliar um conceito com uma imagem, descobrir a qualidade icônica, material, de uma idéia, ou de algo duvidoso".

Na teoria das representações sociais proposta por Moscovici (2003, p.89), são utilizadas, como amostras de pesquisa, as conversações encontradas na sociedade e partilhadas pelos sujeitos. Essas conversações podem estar na forma de discursos, veiculados pelos mais diversos meios de comunicação. As conversações têm o mérito de possibilitar a comunicação entre as pessoas e formar os discursos, ou seja, as representações que são modificadas e alteradas no decorrer das conversações. Sendo assim, lidando com depoimentos, a pesquisa apenas poderia ser do tipo qualitativo, caracterizada pela forma não estatística de analisar, interpretar e apresentar os resultados.

Para analisar os dados, utilizou-se a técnica chamada Discurso do Sujeito Coletivo (DSC), que é "[...] uma proposta de organização de dados qualitativos de natureza verbal, obtidos de depoimentos, artigos de jornal, matérias de revistas semanais, cartas, papers, revistas especializadas, etc." (LEFÈVRE; LEFÈVRE, 2003, p.15). O DSC consiste em uma estratégia diferente de categorização, pois não separa os discursos individuais dos coletivos, mas une-os em uma fala coletivizada.

Uma das bases do DSC é a semiótica peirciana, principalmente as contribuições de Peirce (2000) relativas à cadeia semiótica. O discurso é entendido na concepção peirciana como signo de um objeto que evolui mediante as várias releituras que recebe, afastando-se do objeto de representação cada vez que é realizada uma nova releitura.

Para tratar os dados com a técnica DSC utilizaram-se as figuras metodológicas: expressões-chave, idéias centrais, ancoragem e discurso do sujeito coletivo. "As expressões-chave (ECH) são pedaços, trechos ou transcrições literais do discurso que devem ser sublinhadas, iluminadas, coloridas pelo pesquisador, e que revelam a essência do depoimento [...]" (LEFÈVRE; LEFÈVRE, 2003, p.17). Essas expressões-chave servem para comprovar a veracidade das idéias centrais e das ancoragens, estando o material discursivo em estado bruto. A idéia central (IC) é a descrição precisa e direta dos significados do conjunto 
dos discursos que foram analisados e destacados nas expressões-chave. Ancoragem (AC) é a figura metodológica que indica a teoria, o pressuposto, a corrente de pensamento e o fundo do conhecimento que o sujeito compartilha e aceita de maneira natural para representar um dado fenômeno da realidade. Finalmente, o discurso do sujeito coletivo (DSC) é um discurso que resume o exposto nas várias expressões-chave, tomando por base as idéias centrais ou as ancoragens que são comuns a um determinado discurso, redigido na primeira pessoa do singular (LEFÈVRE; LEFÈVRE, 2003, p.18). O DSC une os discursos semelhantes e complementares dos sujeitos em um único discurso que representa a manifestação do pensamento do grupo em relação a um tema específico.

A técnica de coleta de dados empregada na pesquisa foi o questionário, constituído de uma lista de questões abertas (oito perguntas no total) relativas à compreensão que os pesquisadores têm da Ciência da Informação: definição, limites, relações, história etc. Os pesquisadores foram contatados por telefone e correio eletrônico, e, em seguida, fez-se a apresentação da pesquisa seguida pelo convite para dela participar.

A população da pesquisa foi composta de pesquisadores com Bolsa de Produtividade em Pesquisa (PQ), do CNPq, da área de Ciência da Informação, contando-se as bolsas em curso em 2004. Nessa condição, verificou-se a existência de 30 pesquisadores, segundo os dados obtidos no site da instituição que concede as bolsas, no dia 19 de fevereiro de 2004 (CONSELHO..., 2004). A população foi definida a partir do critério financiamento-institucional e os sujeitos delimitados intencionalmente pelo requisito mais tempo com bolsa da agência. Entendeu-se que esse maior tempo como bolsista tenha contribuído para o aprimoramento da compreensão do pesquisador a respeito do campo da Ciência da Informação. Para efetuar esse refinamento, incluiu-se a classe categoria dos pesquisadores. Foi escolhida a categoria I (níveis A, B e C), que se acreditou agrupar os pesquisadores, teoricamente, mais experientes e produtivos do campo, os quais possivelmente estariam vinculados à agência há mais tempo. $\mathrm{O}$ grupo analisado compreendeu onze pesquisadores: dois IA, dois IB e sete IC. Desses pesquisadores nove colaboraram com a realização da pesquisa.

A aplicação do pré-teste foi essencial para avaliar a precisão das perguntas do questionário. Os sujeitos do pré-teste foram os pesquisadores da categoria Il (nível A) que estavam com bolsa do CNPq em curso desde 2003, porque se aproximam do perfil dos sujeitos principais da pesquisa. Na condição de bolsistas $\mathrm{PQ}$, da categoria II nível A, com bolsa desde 2003, encontraram-se três pesquisadores. Os dados obtidos no pré-teste foram utilizados apenas para ajustar e adequar as questões do instrumento.

A fase de coleta de dados, envio e recebimento das respostas ocorreu entre os meses de julho e outubro de 2004. A interpretação dos dados pautou-se na epistemologia crítica, entendida como a que é "[...] fruto da reflexão que os próprios cientistas estão fazendo sobre a ciência em si mesma. Trata-se de uma reflexão histórica feita pelos cientistas sobre os pressupostos, os resultados, a utilização, o lugar, o alcance, os limites e a significação socioculturais da atividade científica." (JAPIASSÚ, 1977, p.138).

\section{AS REPRESENTAÇÕES DOS PESQUISADORES DO CAMPO DA C I Ê N C I A D A I N F O R M A Ç Ã O: relações com a sociedade brasileira}

$\mathrm{Na}$ análise dos discursos dos pesquisadores em Ciência da Informação e bolsistas de produtividade do CNPq, grupo que se acredita concentrar o pensamento da Ciência da Informação no país, verificou-se a presença de representações da realidade social tal como tratadas na teoria das representações sociais. Cada sujeito expressa um conceito teórico do campo da Ciência da Informação e pensamentos a respeito da atuação e relação da Ciência da Informação com a sociedade brasileira, bem como emite juízos sobre a história, a extensão e o raio de ação desse campo. Neste trabalho, pretende-se somente analisar o discurso coletivo referente a esse campo da ciência e sua relação com a sociedade brasileira.

O discurso exposto é produto da reunião de todas as respostas dadas às questões do instrumento de coleta de dados que dizem respeito à relação do campo da Ciência da Informação com a sociedade brasileira. Representa o pensamento dos participantes da pesquisa sobre o campo da Ciência da Informação no país. Tentou-se, na medida do possível, utilizar a maioria das expressões-chave de cada respondente; cada trecho foi considerado de suma importância para compor o discurso coletivo. Mesmo assim, al- 
guns trechos foram excluídos por já estarem expressos nas falas de outros sujeitos individuais.

Sugere-se que o discurso do grupo seja lido como a fala elaborada por um suposto sujeito social que se expressa em nome de todos os indivíduos. As representações emitidas nos discursos são o que Moscovici (2003) entende como a tentativa de produção do familiar. O sujeito idealizado também pode ser entendido no sentido de Durkheim (1994, p.43): a entidade que possui uma natureza diversa da dos indivíduos tomados isoladamente, mas dependente, logicamente, das consciências individuais para se manifestar e para compor as representações que denominou de coletivas. A seguir, apresenta-se o discurso coletivo referente a essa ciência e sua relação com a sociedade brasileira.

A Ciência da Informação no Brasil nasceu na segunda metade dos anos 50; pelo tumulto da explosão da informação (Unesco) convenceu a então Diretora do Instituto Brasileiro de Informação em Ciência e Tecnologia (IBICT) Célia Ribeiro Zaher a criar no Brasil e no IBICT, uma especialização lato sensu em 1956 sobre informação para agricultura. É marcada pela presença forte do Estado e das instituições estatais na conformação do campo no país, aliada às políticas de controle bibliográfico a cabo da UNESCO e organismos brasileiros, dentre eles o antigo IBBD, hoje IBICT; em suas vertentes de ensino, de pesquisa e de serviços, e sob a forte influência teórica norte-americana e inglesa. Em 1970 foi criado o mestrado em Ciência da informação do IBICT, em convênio com a Universidade Federal do Rio de Janeiro que nascia com enfoque completamente diferente da Biblioteconomia. O campo no Brasil nasce em 1970 com o Curso de Mestrado em Ciência da Informação e com a criação dos primeiros cursos de Mestrado. O curso do IBICT foi o primeiro programa de pós-graduação na área a iniciar estudos em nível de doutorado na década de 80. O Programa de Pós-Graduação em Ciência da Informação (PPGCI) do IBICT nos seus primórdios contou com renomados professores da área, oriundos de universidades americanas e inglesas. Os demais cursos hoje denominados como Ciência da Informação migraram da área da Biblioteconomia e ainda possuem resquícios dessa área. A Ciência da Informação nasceu com um currículo e com conteúdos novos, dava à Biblioteconomia o seu valor de organização, administração e controle dos estoques de informação mas transcendia esta prática. Todos os programas criados com o nome de $\mathrm{Cl}$ a partir do IBICT procuravam modificar o status do profissional que formavam. Mas os conteúdos permaneceram os mesmos, isto é, ensina-se Biblioteconomia com o nome de Ciência da Informação.

A tônica da área no país esteve, em grande medida, voltada para a informação científica e tecnológica e, notadamente a partir da década de 80 , sob uma maior influência francesa, voltou-se para aspectos como a dimensão social da informação. Aspecto fundamental para o crescimento acadêmico da área, no país, foram os cursos de pós-graduação, para a formação de uma comunidade própria do campo, além dos seus ascendentes dos cursos de Biblioteconomia, sobretudo. Os cursos e programas de pós-graduação se construiriam a partir de um grupo de pesquisadores pioneiros, que tiveram sua capacitação no exterior e, em voltando ao Brasil, souberam formar novas gerações de pesquisadores bem como liderar a pesquisa na área, permitindo um cotejo e uma reflexão dos teóricos estrangeiros à luz da realidade nacional e latino-americana. A Ciência da Informação consolida-se como área do saber, a partir do final dos anos de 1980, quando se deu a criação da Associação Nacional de Pesquisa e Pós-Graduação em Ciência da Informação e Biblioteconomia (ANCIB), motivando as discussões e as publicações de pesquisas. Portanto, as publicações e as discussões, em encontros da área, marcaram a consolidação da Ciência da Informação como saber científico.

A Ciência da Informação se relaciona com informação em ciência e tecnologia; sua importância para a sociedade brasileira é a mesma dada a ciência e tecnologia. A área se formou em ambientes estatais tradicionalmente distanciados da sociedade, por enquanto são dois mundos que se ignoram ou não se conhecem. Mas podemos tomar como parâmetro deste significado o número de cursos de pós-graduação em Ciência da Informação, hoje num total de nove (9), IBICT, Universidade Federal de Minas Gerais (UFMG), Universidade de Brasília (UnB), Universidade Federal da Paraíba (UFPB), Pontifícia Universidade Católica de Campinas (PUC-CAMPINAS), Universidade de São Paulo (USP), Universidade Estadual Paulista (UNESP), Universidade Federal da Bahia (UFBA) e Universidade Federal de Santa Catarina (UFSC), ou os recursos aplicados pelo CNPq ou Coordenação de Aperfeiçoamento de Pessoal de Nível Superior (CAPES) para a área, ainda bem peque- 
nos, ou as políticas públicas brasileiras, como a Sociedade da Informação, praticamente desativada. Além disso, entendendo que seja pela produção de conhecimento na área, diríamos que se têm feito muitas coisas, mas muitas vezes dispersas, localizadas, justapostas; falta consolidar uma abordagem mais ampla e estratégica das questões e programas de pesquisa, no nível do pais, de regiões, de setores de atividade. Nesse sentido, a Ciência da Informação significa um importante veículo para o desenvolvimento científico e tecnológico, por um lado, e social, por outro, investigando elementos envolvidos na produção, processamento e uso de informação em diferentes setores de atividades (ensino, pesquisa, gestão e avaliação).

A Ciência da Informação teve um crescimento lento. O número de programas de pós-graduação ainda é pequeno. A área não adota uma política de conhecimento (se dar a conhecer) e de convencimento (mostrar o seu potencial enquanto área do conhecimento) em relação ao público externo. Sem isso o reconhecimento da área fica prejudicado, afetando, conseqüentemente, sua avaliação de desempenho enquanto área do conhecimento. Temos problemas próprios e problemas comuns com outras áreas do conhecimento. A Ciência da Informação no Brasil se fez mais atuante e expressiva pela institucionalização e fortalecimento dos programas de pós-graduação e o desenvolvimento das suas linhas de pesquisa, apesar da sua produção ainda modesta, se comparada a outras áreas e/ou disciplinas. O campo encontra-se em crescimento no país, como demonstram o aumento de programas de pós-graduação na área, o crescimento da produção científica na área e, ainda, o importante papel desempenhado pela ANCIB como elemento catalisador e impulsionador da comunidade científica da área, no País.

A área cada vez mais se revela como ciência, na medida em que novos conhecimentos são produzidos e compartilhados pelo conjunto de pesquisadores que constroem a Ciência da Informação no Brasil. Hoje existe uma capacidade técnica, humana e científica básica instalada para fazer expandir e multiplicar as atividades de pesquisa e formação em Ciência da Informação no país. Os grandes desafios no momento são: a expansão da pesquisa e da divulgação do conhecimento produzido; a criação de programas e linhas de pesquisa em regiões menos favorecidas economicamente e, por via de conseqüência, com deficiências acadêmicas e científicas; a internacionalização dos programas, seus pesquisadores e pesquisas; a criação de projetos de pesquisa e linhas de financiamento que privilegiem a criação de programas de acesso, inclusão e apropriação digital, em bases científicas e éticas concernentes com as necessidades da sociedade brasileira; a fixação de recém-doutores em programas de pós-graduação de modo eqüitativo nas diferentes regiões do país; o estabelecimento de uma agenda de pesquisa para a área de modo concertado, discutido e amadurecido pela comunidade da Ciência da Informação juntamente com as agências de avaliação e fomento à pesquisa e à pós-graduação.

\section{Um discurso da história da Ciência da Informação no Brasil}

A memória coletiva da Ciência da Informação no Brasil é formada, entre outras coisas, por aqueles fatos que os pesquisadores acreditam terem feito parte da história do campo. Fatos e acontecimentos elencados pelo grupo foram compreendidos como os mais relevantes para a institucionalização da Ciência da Informação no país. De maneira alguma essa é uma tentativa de estabelecer uma história completa e exaustiva da Ciência da Informação, pois isso demandaria muitas outras pesquisas e a recorrência a fontes e a estratégias metodológicas de diversas naturezas. Tendo consciência disso, consideram-se essenciais as afirmações expostas a seguir uma vez que destacam aquilo que é o mais importante para o grupo e que contribuiu efetivamente para o desenvolvimento do campo no país.

As representações da história da Ciência da Informação presentes no discurso dos pesquisadores desdobradas em um conjunto de acontecimentos e fatos e suas conseqüências conservam semelhanças com os tópicos centrais sobre o assunto já registrados pela literatura brasileira da Ciência da Informação. Dentre os estudos produzidos que destacam a história dessa ciência no país, pode-se citar os trabalhos de Barreto (1999, 2002), Pinheiro e Loureiro (1995), Pinheiro (2000), Vieira (1995), Robredo (2003), Población e Noronha (2003), Gomes e Zaher (1972), Dias (2000), Christovão (1995) e Barbosa et al. (2000).

Um dos aspectos centrais expressos na fala dos respondentes foi o reconhecimento do papel de instituições das mais diversas naturezas para a forma- 
ção da Ciência da Informação. Instituições, nesse caso, são os órgãos estatais que dão suporte ao desenvolvimento científico e tecnológico expressamente por meio das políticas de implementação e melhoria dos sistemas de controle e disseminação da informação científica. Agências de fomento à pesquisa, institutos de informação e bibliografia, organizações científicas e profissionais e o próprio Estado deram e dão sustentação às ciências em geral e à Ciência da Informação de modo particular. É como se essas entidades e organismos corporificassem uma ciência, entendida de forma ampla - sendo bem mais que a simples aplicação do método científico por pessoas privilegiadas, eleitas por sua vontade, prazer e compromisso pelo conhecer.

O IBBD foi empreendedor no processo de construção e divulgação da Ciência da Informação no Brasil. Segundo o discurso do grupo, na década de 1950, época da fundação do instituto, sucedeu-se o que ficou conhecido pelos países desenvolvidos por "explosão da informação". Isso pode significar que a fundação do IBBD representou a resposta brasileira a uma tendência mundial, buscando com sua criação a adequação às iniciativas de controle bibliográfico da literatura científica. Além da fundação do IBBD, outras ações foram imprescindíveis para a efetiva institucionalização da Ciência da Informação no país, como a abertura, em 1970, do curso de mestrado do IBBD.

Em outras falas do grupo a história da Ciência da Informação no Brasil começa a ser relatada a partir do curso de mestrado do IBBD, que se acredita ter proporcionado a consolidação da expressão "Ciência da Informação" junto à comunidade científica e profissional. Entretanto, nesse aspecto simplista de representar o surgimento da Ciência da Informação não se leva em conta as transformações políticas, econômicas e científicas que fizeram ou exigiram uma ciência que complementasse o Sistema de Ciência e Tecnologia ( $C \& T$ ) do país, resolvendo problemas e provendo serviços ligados aos sistemas de informação científica e tecnológica. De modo geral, o contexto político de formação da Ciência da Informação permitiu que as Nações-Estados visualizassem o setor de $C$ \& T como um instrumento de desenvolvimento tecnológico e econômico dos países desenvolvidos e em desenvolvimento.

Por outro lado, o discurso coletivo dos pesquisadores não tratou da Documentação, de seu papel, de suas técnicas e da introdução de suas novas idéias relativas à concepção dos registros bibliográficos. A categoria bibliotecária e os cursos de Biblioteconomia pouco são citados. Porém, as primeiras experiências da Documentação foram as que permitiram a ligação da comunidade profissional brasileira com os círculos da Documentação e de tratamento da informação internacionais. Já os bibliotecários possibilitaram a expansão da Ciência da Informação nos espaços de formação e atuação profissional.

Em resumo, é como se o grupo de pesquisadores dissesse, de uma só vez, a idéia predominante da história da Ciência da Informação no Brasil de maneira objetiva e clara: nasceu com o IBBD, em 1950, com os problemas enfrentados em todo o mundo pela explosão da informação; ganhou espaço acadêmico com a criação do mestrado no mesmo instituto e com a criação de outros programas de pós-graduação; consolida-se com a fundação da associação científica e aumentam as publicações e os debates no circuito acadêmico. Contou com a mobilização de organismos externos, como organizações multilaterais (Unesco), e recebeu interferência direta das políticas de desenvolvimento da Nação-Estado em que está inserida.

Verifica-se no discurso coletivo um processo de distinção, que consiste na separação, pelo menos no nível discursivo, do que é próprio da Biblioteconomia e do que é da competência da Ciência da Informação. É com essa perspectiva da situação que alguns enunciados são elaborados no interior da comunidade científica. A intenção, pelo que parece, é mostrar a Ciência da Informação como uma entidade auto-suficiente, distante dos "resquícios" provenientes da Biblioteconomia, sejam eles objeto, método, teoria ou conceitos.

É possível interpretar as expressões-chave que tratam desse tema da seguinte forma: a Biblioteconomia tornou-se uma interferência para um ideal científico da Ciência da Informação e demonstra insuficiência teórica no que tange às questões da informação científica principalmente. A prática profissional dos bibliotecários também não condiz com a postura investigativa do cientista da informação. Discursos que caminham para essa direção motivam e/ou intencionam alterar os esquemas conceituais da realidade social e reconfigurar as relações de poder entre os pesquisadores e entre os campos científico e profissional. Atuam no nível simbólico buscando legitimar a separação que desejam imprimir à prática, isto é, "[...] traçar, por 
meio do dizer, as fronteiras entre os grupos e também entre o sagrado e o profano, o bem e o mal, o vulgar e o distinguido" (BOURDIEU, 1989, p. 151). É organizando o discurso que o sujeito tenta separar os objetos da realidade social, distinguir Ciência da Informação de Biblioteconomia; distinguir os programas de pós-graduação "puros" em Ciência da Informação dos maculados de Biblioteconomia.

\section{A Ciência da Informação e a sociedade brasileira: os pontos de (des)conexão}

Aproximando-se das representações que acentuam os problemas da Ciência da Informação no Brasil, o grupo de respondentes argumentou que o campo quase não tem significado para a sociedade brasileira, e não é valorizado pelos grupos que estão à frente das decisões políticas e científicas e pela população em geral. A síntese dessas idéias mostra que a Ciência da Informação tem pouco ou nenhum significado para a sociedade.

Em outras passagens do discurso coletivo, ela é concebida como uma ciência que contribui, por meio de pesquisas, com o desenvolvimento científico, tecnológico e social do país. Nesse sentido, torna-se veículo que possibilita esse desenvolvimento. Uma das lógicas subjacentes é que a Ciência da Informação atuaria, em segundo plano, no âmbito científico e tecnológico para a consolidação do desenvolvimento social, o que subentenderia um relacionamento com o desenvolvimento nacional.

A crença no desenvolvimento social por meio do desenvolvimento científico e tecnológico, passando em primeiro lugar (evidentemente) pelo econômico, é um argumento que reforça a legitimação da Ciência da Informação junto à sociedade. Bunge (1989) demonstra o conteúdo dessa crença de forma surpreendente em seus argumentos. Esse ponto de vista é assumido de maneira tão simples - quase natural -, tal como encontrado em trechos do discurso analisado. Nesse sentido, a Ciência da Informação não estaria ligada diretamente ao desenvolvimento do social, como verificado, pois a sociedade nem ao menos conhece esse campo. Talvez o conceito de sociedade utilizado pela fala do grupo não corresponda ao da maioria da população, encobrindo o predomínio de algumas coletividades, a saber: elites burocráticas, Estado, grupos empresariais e produtivos.

\section{Avaliação da Ciência da Informação no Brasil: problemas, avanços e desafios}

Um conjunto de aspectos foi citado como determinante tanto para o bom quanto para o fraco desempenho da Ciência da Informação. Esses aspectos compõem o que o grupo pensou como essencial para que a Ciência da Informação se desenvolva e as questões prioritárias a serem solucionadas com o intuito de alcançar, sobretudo, a condição de ciência tal como outros campos de pesquisa estabelecidos e privilegiados socialmente. De modo geral, tanto as críticas que revelam aspectos positivos quanto as que apontam características negativas fazem parte do pensamento do grupo sobre a performance da Ciência da Informação no país, o que, de forma direta, revela a capacidade de reflexividade do grupo, conseguindo ver a si próprio e o fazer que executa.

$\mathrm{Na}$ avaliação do grupo investigado enfatizam-se a fragilidade e os problemas enfrentados pelo campo da Ciência da Informação. Aponta-se como uma das causas do fraco desempenho e da falta de identidade psicológica e acadêmica, o seu relacionamento estreito com a Biblioteconomia. Nessa ótica, a Biblioteconomia teria se beneficiado da Ciência da Informação para elevar o status profissional dos bibliotecários. Visto por outro ângulo, não se observou, porém, a cumplicidade das relações entre esses campos, pois se verifica que foi da Biblioteconomia que a Ciência da Informação obteve um espaço propício para institucionalizar-se e afirmar-se socialmente. A lógica expressa nesse discurso, a causa do baixo desempenho e da falta de identidade, é o relacionamento estreito com a Biblioteconomia, que se apropriou do título "Ciência da Informação" para continuar a reproduzir os mesmos conteúdos já adquiridos.

Além disso, reserva-se ao programa de pós-graduação do Instituto Brasileiro de Informação em Ciência e Tecnologia o monopólio da reprodução legítima, nos termos de Bourdieu (1983, 2004), de especialistas e pesquisadores em Ciência da Informação, esses considerados genuínos produtores do conhecimento científico da área. Como exposto na fala do "social", esses indivíduos deteriam o poder pleno de falar em nome da Ciência da Informação no país, enquanto os demais pesquisadores, formados nos programas com o rótulo "Ciência da Informação", mas que em essência são de Biblioteconomia, não deteriam tal direito. Adistinção no discurso pode servir, 
como indicado anteriormente, para efetivar ou refletir uma distinção que se pretende à prática social.

No que toca os desafios que precisam ser superados, o grupo especifica os mais urgentes, que, em síntese, influenciam o efetivo crescimento do campo. Além do desenvolvimento da pesquisa em todos os sentidos, faz-se urgente a inserção da Ciência da Informação em outros campos sociais, a fim de propiciar a criação de programas de, por exemplo, inclusão digital, além de estimular o desenvolvimento eqüitativo das diversas regiões do país mediante a instalação de novos programas de pós-graduação. Complementa-se afirmando que, para discutir a agenda de pesquisa do campo, será necessário contar com a participação da comunidade científica e das agências de fomento e avaliação, indicando, provavelmente, que os setores chamados a decidir os rumos do campo estão ligados mais à produção e à gestão da informação científica do que à sociedade brasileira propriamente dita.

Contudo, apontou-se para os avanços alcançados pela comunidade científica do campo, bem como para o desenvolvimento da Ciência da Informação, o que corrobora as afirmações confiantes no seu crescimento, apesar dos desafios a serem superados. No que diz respeito ao progresso do campo, uma das vias para verificá-lo seria a produção científica, que, segundo a fala do grupo, está em ritmo acelerado e depende da circulação desses conhecimentos junto aos pares. O critério presente no grupo são os indicadores, os mesmos dados sob os quais trabalham os gestores da ciência e tecnologia, presumindo-se que desse modo os indicadores trariam desenvolvimento teórico-metodológico. Ainda no que se refere ao crescimento, destaca-se o papel da associação de pesquisa ANCIB como articuladora das ações do grupo e que centraliza as questões da comunidade visando promover seu avanço. Além disso, conta-se com o apoio dos programas de pós-graduação para caracterizar materialmente esse avanço, o que implica a produção de novos conhecimentos, sua divulgação, reprodução de quadros de pesquisadores e fixação de linhas e programas de pesquisa bem delineados.

\section{CONSIDERAÇÕ ES FINAIS}

Conforme se acredita ter explicitado, o discurso coletivo estudado está permeado de idéias centrais que, corriqueiramente, são levantadas, assumidas e reforçadas pelo grupo de pesquisadores. Algumas dessas idéias centrais puderam ser resgatadas, analisadas e interpretadas, tendo sido listadas as mais significativas para o exposto neste trabalho: a) a definição e a afirmação da Ciência da Informação no Brasil por intermédio da diferença em comparação aos outros campos profissionais, próximos e relacionados (a afirmação da identidade passa, principalmente, pela relação entre Ciência da Informação e Biblioteconomia); b) a aceitação de que sua história foi construída, de modo substancial, por meio das ações executoras implementadas por instituições ligadas ao Estado, o que provoca o questionamento: qual a participação da comunidade científica nas decisões sobre a construção do campo da Ciência da Informação no Brasil?; c) a aceitação da distância histórica entre Ciência da Informação e sociedade brasileira; e d) o reconhecimento dos avanços, dos problemas e dos desafios a serem enfrentados pelos agentes do campo.

Conscientizar-se desses antagonismos, próprios da Ciência da Informação brasileira, é indispensável para a constituição da memória social do grupo, definida como o conjunto de conhecimentos e suposições de que os próprios pesquisadores e profissionais se utilizam para falar a respeito da Ciência da Informação. Em virtude disso, as representações resgatadas nesta pesquisa podem ser assimiladas como a expressão da máxima consciência possível do grupo, considerando-se o período de realização do estudo e o conjunto de depoimentos analisados; isto é, a compreensão que um grupo pode atingir a respeito de uma dada situação, uma mensagem ou informação recebida (GOLDMANN, 1970, p.43). Em outras palavras, o conjunto dos discursos dos pesquisadores da Ciência da Informação no Brasil, que foi analisado, delimita o alcance e a extensão da consciência social do grupo. Conseqüentemente, poderá orientar os discursos que, porventura, os denominados profissionais da informação terão sobre esse campo científico.

Nesse sentido, algumas afirmações que incitam generalizações das questões suscitadas devem ser consideradas como simples índices - ou mesmo hipóteses - para estudos futuros que poderão auxiliar na tarefa árdua de resgatar as representações sociais operantes no campo da Ciência da Informação no país. Esse é um passo fundamental para que essa ciência consiga responder aos seus anseios como comunidade científica e reduzir a distância em relação à sociedade brasileira. 


\section{REFERÊNCIAS}

ASSOCIAÇÃO NACIONAL DE PESQUISA E PÓS-GRADUAÇÃO EM CIÊNCIA DA INFORMAÇÃO E BIBLIOTECONOMIA (ANCIB). Apresentação da ANCIB. [S. I.]. Disponível em: <http://www.ancib.org.br>. Acesso em: 29 dez. 2004.

BARBOSA, R.R. et al. Novo nome e novo paradigma: da biblioteconomia à ciência da informação. Perspectivas em Ciência da Informação, Belo Horizonte, v.5, n.especial, p.81-91, 2000.

BARRETO, A. Os destinos da ciência da informação: entre o cristal e a chama. Informação \& Sociedade: Estudos, João Pessoa, v.9, n.2, 1999. Disponível em: <http://www. informacaoesociedade.ufpb.br>. Acesso em: 3 maio 2004.

BARRETO, A. O tempo e o espaço da ciência da informação. Transinformação, Campinas, v.14, n.1, p.17-24, 2002.

BERGER, P.L.; LUCKMANN, T. A construção social da realidade: tratado de sociologia do conhecimento. 22.ed. Petrópolis: Vozes, 2002.

BOURDIEU, P. O campo científico. In: ORTIZ, R. (Org.). Pierre Bourdieu: sociologia. São Paulo: Ática, 1983.

BOURDIEU, P. Opoder simbólico. Lisboa: DIFEL; Rio de Janeiro: Bertrand Brasil, 1989.

BOURDIEU, P. Os usos sociais da ciência: por uma sociologia clínica do campo científico. São Paulo: Unesp, 2004.

BUNGE, M. Ciência e desenvolvimento. São Paulo: EDUSP, 1989. (Coleção O Homem e a Ciência; 11).

CASTRO, C.A. História da biblioteconomia brasileira: perspectiva histórica. Brasília: Thesaurus, 2000.

CHRISTOVÃO, H.T. A ciência da informação no contexto da pós-graduação do IBICT. Ciência da Informação, Brasília, v.24, n.1, p.31-35, 1995.

CONSELHO NACIONAL DE DESENVOLVIMENTO CIENTÍFICO E TECNOLÓGICO (CNPq). [Brasília]. Disponível em: <http://www.cnpq.br>. Acesso em: 19 fev. 2004.

DIAS, E. W. Biblioteconomia e ciência da informação: natureza e relações. Perspectivas em Ciência da Informação, Belo Horizonte, v.5, n.especial, p.67-80, 2000.

DIAS, E.W. Ensino e pesquisa em ciência da informação. DataGramaZero - Revista de Ciência da Informação, Rio de Janeiro, v.3, n.5, 2002. Disponível em: <http://www. dgz.org.br>. Acesso em: 1 set. 2003.

DURKHEIM, É. Sociologia e filosofia. São Paulo: Ícone, 1994.

FONSECA, M.O. Ciência da informação: denominação de curso e diretrizes curriculares. Transinformação, Campinas, v.14, n.1, p.101-104, 2002.

GOLDMANN, L. Importância do conceito de consciência possível para a comunicação. In: O CONCEITO de informação na ciência contemporânea: Colóquios Filosóficos Internacionais de Royaumont. Rio de Janeiro: Paz e Terra, 1970. v.2, p.38-68.

GOMES, H.E.; ZAHER, C.R. A experiência do IBBD na preparação de cientistas da informação. In: SEMINÁRIO LATINO-AMERICANOSOBRE PREPARAÇÃODE CIENTISTAS DA INFORMAÇÃO, 1972, México, DF. Anais... Rio de Janeiro: IBBD, 1972. p. 315-323.

JAPIASSÚ, H. Introdução ao pensamento epistemológico. 2.ed. Rio de Janeiro: F. Alves, 1977.

LEFÈVRE, F.; LEFÈVRE, A.M.C. O discurso do sujeito coletivo: um novo enfoque em pesquisa qualitativa (desdobramentos). Caxias do Sul: UDUCS, 2003. (Coleção Diálogos).

LEMOS, A.A.B. Estado atual do ensino de biblioteconomia no Brasil e a questão da ciência da informação. In: SEMINÁRIO LATINO-AMERICANO SOBRE PREPARAÇÃODE CIENTISTAS DAINFORMAÇÃO, 1972, México, DF. Anais... Rio de Janeiro: IBBD, 1972. p. 11-19.

MOSCOVICI, S. Representações sociais: investigações em psicologia social. Petrópolis: Vozes, 2003.

OLIVEIRA, M. A pesquisa científica na ciência da informação: análise da pesquisa financiada pelo CNPq. Perspectivas em Ciência da Informação, Belo Horizonte, v.6, n.2, p.143-156, 2001.

OLIVEIRA, F.O.; WERBA, G.C. Representações sociais. In: JACQUES, M.GC. et al. Psicologia social contemporânea: livro-texto. 6.ed. Petrópolis: Vozes, 2002. p. 104-117.

PEIRCE, C.S. Semiótica. 3.ed. São Paulo: Perspectiva, 2000.

PINHEIRO, L.V.R. Infra-estrutura da pesquisa em ciência da informação no Brasil. DataGramaZero - Revista de Ciência da Informação, Rio de Janeiro, v.1, n.6, dez. 2000. Disponível em: <http://www.dgz.org.br>. Acesso em: 1 set. 2003.

PINHEIRO, L.V.R.; LOUREIRO, J.M.M. Traçados e limites da ciência da informação. Ciência da Informação, Brasília, DF, v.24, n.1, p.42-53, 1995.

POBLACIÓN, D.A.; NORONHA, D.P. Rumos da Comunidade Brasileira de Pesquisadores em Ciência da Informação: desafios do século XXI. In: ENCONTRO NACIONALDE PESQUISAEM CIÊNCIA DA INFORMAÇÃO, 5., 2003, Belo Horizonte. Anais... Belo Horizonte: UFMG, 2003. 1 CD-ROM.

ROBREDO, J. Da ciência da informação revisitada aos sistemas humanos de informação. Brasília: Thesaurus, 2003.

VIEIRA, A.S. Na janela do tempo com o IBBD e Drummond: passagens, transformações e novos desafios em educação. Ciência da Informação, Brasília, DF, v.24, n.1, 1995. Disponível em: <http://www.ibict.br/cienciadainformacao/viewarticle. php? id=573\&layout=abstract $>$. Acesso em: 6 fev. 2005. 